\title{
Evaluation of the Relationship between Emotional Intelligence and Anger Control in Nurses and Midwives of Kashani Hospital in Southern Iran in 2018 - A Descriptive-Analytical Study
}

\author{
Fereshteh Daneshi ${ }^{1}$, Maryam Mirzaei $^{2}$, Mohammad Salar Motaghi $^{3}$, Motahare Pilevarzadeh ${ }^{4}$, Neda Dastyar ${ }^{5}$ \\ ${ }^{1}$ Department of Nursing, Jiroft University of Medical Sciences, Kerman, Iran. ${ }^{2}$ Department of Obstetrics and \\ Gynaecology, Jiroft University of Medical Sciences, Kerman, Iran. ${ }^{3}$ Member of Student Research Committee, Jiroft \\ University of Medical Sciences, Kerman, Iran. ${ }^{4}$ Department of Nursing, Jiroft University of Medical Sciences, Kerman, \\ Iran. ${ }^{5}$ Department of Midwifery, Jiroft University of Medical Sciences, Kerman, Iran.
}

\section{ABSTRACT}

\section{BACKGROUND}

Emotional intelligence is one of the effective factors in managing stressful behaviours. Nurses and midwives are exposed to a variety of stressful behaviours in the workplace every day. The purpose of this study was to evaluate the relationship between emotional intelligence and anger control in nurses and midwives of Kashani hospital in southern Iran in 2018.

\section{METHODS}

This descriptive cross-sectional study was conducted among 102 nurses and midwives in Ayatollah Kashani Hospital in Jiroft in 2018. Participants were selected through available sampling. Data was collected using the Shate Emotional Intelligence Questionnaire and Anger Control Questionnaire. The collected data were entered into SPSS software and analysed by Pearson's correlation coefficient.

\section{RESULTS}

The mean age of participants was 30.97 \pm 6.101 years. Results showed that most of the participants were married (80.4\%), employment status (Tarhi) was $31.4 \%$, had bachelor's degree $(90.2 \%)$, was a midwife $(60.8 \%)$, and was in morning shift $(52.9 \%)$. There was a significant correlation between emotional intelligence and anger $(\mathrm{p}<0.001)$.

\section{CONCLUSIONS}

According to the results of the study, attention to emotional intelligence among nurses and midwives is very important and is an important factor in managing stressful relationships between them.

\section{KEY WORDS}

Emotional Intelligence, Anger Control, Nurses, Midwives
Corresponding Author:

Neda Dastyar,

Department of Nursing,

Jiroft University of Medical Sciences,

Kerman, Iran.

E-mail: dr.neda@yahoo.com

DOI: $10.14260 / \mathrm{jemds} / 2019 / 811$

Financial or Other Competing Interests: None.

How to Cite This Article:

Daneshi F, Mirzaei M, Motaghi MS, et al. Evaluation of the relationship between emotional intelligence and anger control in nurses and midwives of kashani hospital in Southern Iran in 2018- a descriptiveanalytical study. J. Evolution Med. Dent. Sci. 2019;8(50):3744-3748, DOI:
Submission 12-10-2019,

Peer Review 28-11-2019,

Acceptance 04-12-2019,

Published 16-12-2019. 


\section{BACKGROUND}

Emotional intelligence is a multidimensional construct involving the interaction between emotion and cognition.(1) Emotional intelligence can be defined as a set of noncognitive capabilities, abilities and skills that enhance one's ability to successfully deal with environmental pressures and demands, resulting in compatible and philanthropic behaviours.(2) One of the variables that can predict creativity is emotional intelligence. Emotional intelligence is a form of social intelligence that is an appropriate predictor of efficacy in certain areas, such as occupational and academic performance and includes the ability to control the feelings and emotions of oneself and others and their differentiation and using this information to guide one's thinking and practice. According to Goleman (1995) Emotional intelligence is the recognition of one's own feelings and its use to make the right decisions in life, the ability to manage mood and mental status, the ability to control impulses, and is in fact the factor that motivates a despaired individual who has Failed to achieve a goal and it also enables individuals to identify themselves and develop proper relationships with people and adaptation to the environment. Individuals with higher emotional intelligence clearly understand their emotions and that of others, are able to manage them, so they deal with problems efficiently and have a positive attitude towards their lives. Theoretical origins of most researches on the concept of emotional intelligence is derived from the work of Salvey and Meyer. In their view, emotional intelligence is a person's capacity to perceive, express, recognize, use, and control his/her emotions in himself/herself and in others.(2)

Anger refers to an emotional state ranging from mild arousal to outrageous anger and often manifests when the way to achieving goals or meeting the needs of individuals is blocked.(2) Aggression is defined as inflicting blatant harm or direct punitive behaviours on other people or objects. Anger control refers to the acceptance and conduct of appropriate behaviours accordant with the environment and environmental changes, and its opposite concept is aggression. Aggression may occur in different contexts and situations and may be directed to inside or outside of the individual. For this reason, the of noun compatibility is commonly used in conjunction with its adjective, and in the written and interactive literature it is common to see terms such as, marital compatibility, educational compatibility, social compatibility, emotional compatibility, and so on. Unmanaged anger often leads to aggression and incompatibility. According to the consensus of many theorists, anger is one of the main emotions of mankind that has been the most studied after fear.

There are many definitions of anger by philosophers and psychologists, but there are two common themes- 1 . The main cause of anger is the threats and frustrations and obstacles that people face. 2. The goal of anger is often defence, struggle and destruction.(3)

It is also difficult to give a precise definition of aggression, and the term has been used in various ways in the ordinary language. Although the structure of anger has some in common with aggression and hostility, these terms are not synonymous. Delucio and Olivier (2005) argue that hostility refers to an aggressive attitude that leads one to aggressive behaviours, whereas aggression refers to a visible behaviour intended to injure.

Anger is a response that is triggered in a variety of situations, such as real or imagined failures, injuries, humiliations or injustices, and may lead to involuntary responses such as hypertension, increased heart rate, sweating, and hyperglycaemia.(3) Anger as one of the components of negative emotion is associated with dropout, delinquent behaviours, mental pathology, general health problems, and a wide range of psychiatric disorders. ${ }^{(4)}$

Due to their sensitive, stressful and service providing job, nurses and midwives are exposed to a variety of work-related stresses and occupational emotions, which may lead to some behaviours, including anger and violence. These behaviours can have adverse physical and psychological effects on people subject to violence. These effects range from emotional discomposures, anger, nervousness, reduced self-esteem, decreased job satisfaction to a tendency to smoke and alcohol.(5) Anger outbreak in care settings can be very devastating; apart from affecting the personal and professional life of nurses, it also leads to reduced quality of care provided to patients, reduced work efficiency, increased absenteeism, burnout, desertion, financial loss, reduced morale and quality of life of employees, emotional reactions such as anger, sadness, impotency, fear, self-blame, decreased job satisfaction, changes in relationships with colleagues and family, feelings of inadequacy and guilt, and direct and indirect financial burden on the economy of health sector, and on society as a whole.(6) In examining the factors affecting anger, it is worth considering the cognitive, social, and personality aspects of the individual.(3) To date, there has been a great deal of research on emotional intelligence and its effects on quality of life, occupational and educational successes, resistance to stress, health, quality of social and marriage relationships, and these studies has indicated the effects of emotional intelligence on success and happiness in life.(7) Symptoms of occupational stress are manifested in three areas of mental, physical and behavioural. Occupational stress is associated with job dissatisfaction, which in turn can lead to depression, blaming, and etc. Physical symptoms of occupational stress include, cardiovascular disease, gastrointestinal diseases and etc. Behavioural symptoms of occupational stress include personal behaviours such as refusal to do occupational responsibilities, and above all, aggressive and quarrelsome behaviours toward colleagues and clients.(8) Studies have also shown that nurses and midwives with high emotional intelligence can control their emotions in difficult situations and make decisions that are focused on a goal. On the other hand, nonetheless, lower emotional intelligence can affect nurses and midwives and their managing ability over difficulties. ${ }^{(9)}$

As a result, a nurse or midwife not only needs knowledge and skills, but also how to deal with the different behaviours of different people. Emotional intelligence plays a key role in the success of those who work in health care, and this skill allows them to think better under stressful situations and to avoid them from wasting time through emotions such as anxiety, fear, and anger, and simply lets them calm their mind 
so that they can find a way to their inner Insight and creative ideas.(10) Due to the many stressors and their subsequent anger in the staff of Ayatollah Kashani Hospital, as the only gynaecological hospital in the south of Kerman province, and the devastating effects of anger and emotional intelligence effect on anger and anger control, as well as due to the novelty of such a study, we decided to conduct this study on midwifery and nursing staff of this hospital.

\section{METHODS}

This is a cross-sectional study. 102 midwives and nurses working in Ayatollah Kashani hospital of Jiroft in 2018 who were eligible for this study were selected by census method. Inclusion criteria for this study were informed consent of participants to participate in the study, having associate's degree or higher, working in the medical departments of Ayatollah Kashani Hospital, and having no other job. As a result, midwives and nurses who do not meet these criteria were excluded from the study. Data collection tools included demographic checklists, 2 Schutte Emotional Intelligence questionnaires and anger control questionnaire. Demographic information checklist: Demographic information of the samples including 8 questions about age, marital status, number of children, type of employment, work experience, education level, job position and shift of work.

\section{Questionnaire Number 1}

Modified Schutte Emotional Intelligence Scale (MSEIS) is our emotional intelligence scale which consists of a 41 -item selfreport questionnaire designed to measure personality emotional intelligence. This questionnaire is, in fact, a modified version of the Schutte et al. (1998) Emotional Intelligence Scale. Questions 12-15-17-22-24-26-35 are related to emotional evaluation scale in self and others, questions 27-11-7-3-28-20-9 are related to emotional adjustment scale, questions 31-6-39-40-23-19-8-36 are related to the scale of exploiting emotions in problem solving, and questions 38-32-37-30-2-16-33 are related to the scale of perception and understanding of emotions. Questions are scored as: $1=$ completely disagree, $2=$ disagree, $3=$ have no opinion, $4=$ agree, $5=$ completely agree, except questions 3 10-12-14-20-22-24-25 -26-39 that are scored as: 1= completely disagree, $2=$ agree, $3=$ disagree, $4=$ disagree, $5=$ totally disagree. The validity and reliability of this questionnaire have been confirmed in various studies in Iran and in a study by Mohammadi et al. (2007), the reliability of this questionnaire was calculated using Cronbach's alpha and it was reported 0.84.(11)

\section{Questionnaire Number 2}

This is a standard questionnaire of anger control consisting of 25 questions in three sections that assesses three subscales of anger (5 questions), anger in personal relationships (10 questions) and anger in social situations (10 questions). Each question has three parts: $\mathrm{A}, \mathrm{B}$, and $\mathrm{C}$ and score of each of theme is 1,3 , and 5 , respectively. The total score of first section of the Anger Control Questionnaire is between 5 and
25 points. A score of 5-10 indicates that the respondent fears of his/her or others anger and never gets angry. A score of 11-17 is a moderate and natural score and indicates the respondent's awareness of anger, and a score above 17 indicates hostile and threatening individuals who have no problem expressing their anger. Questions of the second section deals with the level of anger control or expression of anger in personal and family life, and the questions of the third section are about the level of anger control or expression of anger in social and non-familial situations. The respondent's score must be between 20 and 100 . If the respondent's score in sections two and three is 75 , the respondent will fall into the group of people who express their anger in an open manner and if it is less than 50 , the respondent is a kind of person who never get angry. A score of 51 to 74 indicates anger control. The validity and reliability of this questionnaire has been confirmed in various studies in Iran and the reliability of this questionnaire has been calculated by Ziauddin Reza Khani to be 0.81 using Alpha Cronbach's alpha. ${ }^{(12)}$

\section{Statistical Analysis}

The collected data included the demographic characteristics of the participants (Marital Status, Education, Occupational Position, Employment Status, and work Shift) and anger situation. To describe the demographic characteristics, descriptive tests (Percentage, frequency and mean) were used. Pearson correlation coefficient test was used to examine the relationship between emotional intelligence and anger control. SPSS Version 18.0 for Windows (SPSS Inc., Chicago, IL, USA) was used to analyze the data. Confidence interval of $95 \%$ and a significance level of P-value less than 0.05 was considered significant.

\section{RESULTS}

\begin{tabular}{|c|c|c|}
\hline \multicolumn{2}{|c|}{ Variable } & Number (Percentage \%) \\
\hline \multirow{2}{*}{ Marital Status } & single & $20(19.6)$ \\
\hline & married & $82(80.4)$ \\
\hline \multicolumn{2}{|c|}{ Total } & $102(100)$ \\
\hline \multirow{3}{*}{ Education } & Associate's degree & $2(2)$ \\
\hline & Bachelor's degree & $92(90.2)$ \\
\hline & Master degree & $8(7.8)$ \\
\hline \multicolumn{2}{|c|}{ Total } & $102(100)$ \\
\hline \multirow{4}{*}{ Occupational Position } & ward supervisor & $9(8.8)$ \\
\hline & staff & $6(5.9)$ \\
\hline & nurse & $25(24.5)$ \\
\hline & midwife & $62(60.8)$ \\
\hline \multicolumn{2}{|c|}{ Total } & $102(100)$ \\
\hline \multirow{4}{*}{ Employment Status } & formal employment & $22(21.6)$ \\
\hline & contract employment & $21(20.6)$ \\
\hline & Agreement based & $27(26.5)$ \\
\hline & Plan based & $32(31.4)$ \\
\hline & & $102(100)$ \\
\hline \multirow{3}{*}{ work Shift } & morning & $54(52.9)$ \\
\hline & evening & $35(34.3)$ \\
\hline & night & $13(12.7)$ \\
\hline \multicolumn{2}{|c|}{ Total } & $102(100)$ \\
\hline
\end{tabular}




\begin{tabular}{|c|c|c|c|c|c|c|c|c|c|c|}
\hline \multicolumn{2}{|r|}{ Variables } & 1 & 2 & 3 & 4 & 5 & 6 & 7 & 8 & 9 \\
\hline 1 & $\begin{array}{c}\text { First aspect } \\
\text { of anger }\end{array}$ & 1 & & & & & & & & \\
\hline 2 & $\begin{array}{c}\text { Second aspect } \\
\text { of anger }\end{array}$ & -0.15 & 1 & & & & & & & \\
\hline 3 & $\begin{array}{c}\text { third aspect } \\
\text { of anger }\end{array}$ & 0.06 & -0.16 & 1 & & & & & & \\
\hline 4 & $\begin{array}{c}\text { Total score } \\
\text { of anger }\end{array}$ & $0.47^{*}$ & $0.46^{* *}$ & $0.57^{* *}$ & 1 & & & & & \\
\hline 5 & $\begin{array}{c}\text { First aspect } \\
\text { of emotional } \\
\text { intelligence }\end{array}$ & -0.06 & -0.02 & -0.01 & 0.004 & 1 & & & & \\
\hline 6 & $\begin{array}{l}\text { Second aspect } \\
\text { of emotional } \\
\text { intelligence }\end{array}$ & -0.14 & $0.27^{* *}$ & 0.04 & 0.18 & 0.08 & 1 & & & \\
\hline 7 & $\begin{array}{l}\text { Third aspect } \\
\text { of emotional } \\
\text { intelligence }\end{array}$ & -0.04 & 0.09 & 0.13 & 0.17 & -0.13 & $0.44^{* *}$ & 1 & & \\
\hline 8 & $\begin{array}{c}\text { Fourth aspect } \\
\text { of emotional } \\
\text { intelligence }\end{array}$ & 0.002 & $0.23^{*}$ & 0.13 & $0.29^{* *}$ & 0.06 & $0.62^{* *}$ & $0.35^{* *}$ & 1 & \\
\hline 9 & $\begin{array}{l}\text { Total score } \\
\text { of emotional } \\
\text { intelligence }\end{array}$ & -0.1 & $0.27^{* *}$ & 0.1 & $0.26^{* *}$ & $0.29^{* *}$ & $0.86^{* *}$ & $0.58^{* *}$ & $0.8^{* *}$ & 1 \\
\hline & Table 2. D & eter & Ematic & ion & $\begin{array}{l}\text { Intela } \\
\text { Intell }\end{array}$ & $\begin{array}{l}\text { on bet } \\
\text { gence }\end{array}$ & teer & ige & & \\
\hline & gnificant at 0.0 & level & ${ }^{* *} \mathrm{Si}$ & can & 0.01 & & & & & \\
\hline
\end{tabular}

The mean age of participants was 30.97 years. The results showed that most of the participants' marital status was married (80.4\%), job status was designing (31.4\%), educational degree was bachelor (90.2\%), occupational position was midwifery $(60.8 \%)$, and shift status was morning shift $(52.9 \%)$ (Table 1). Investigation of the relationship between emotional intelligence and anger control showed that anger and emotional intelligence were correlated. 100 samples were included in this study and were analysed for the variables examined in this study (i. e. emotional intelligence and anger control).

The study revealed that the dimensions of anger intelligence with the dimensions of anger in nurses and midwives at 0.01 and 0.05 levels is significant. In other words, people with high emotional intelligence are less angered (Table 2).

\section{DISCUSSION}

The main purpose of this study was to investigate the relationship between emotional intelligence and anger control in staff (Nurses and midwives). Based on the results, there was a statistically significant relationship between emotional intelligence and anger component. Studies on the relationship between emotional intelligence and anger have mainly shown their inverse relationship. Mayer et al. Showed that emotional intelligence has a significant negative relationship with student's violence and behavioural disturbances(13) and this study is in line with the present study. Also, research has shown that emotional intelligence has a positive relationship with self-abstinence and a negative relationship with verbal violence and this finding is also in line with the results of present study.(14) Workplace violence is always a concern for health care staff, an issue which its rate is increasing. Nurses are more at risk of violence because of their direct contact with patients and their companions and, on average, more than 3 times more likely to be exposed to violence than other professionals. Usually, health care staff are initially subjected to verbal violence, threatened, and eventually subjected to physical violence, and it makes sense because when people are dissatisfied with health care services, they will first express their anger as verbal assault (Insult, scorn, and vituperation) then they tend to threatening and eventually commit physical violence. The rate of unreported violence cases was higher than reported violence cases. Other studies have shown that most cases do not report the violence at all unless they had been subjected to physical violence since some nurses believe that unphysical violence are a part of their occupation. In this study, Rasouli and his colleagues concluded that there was a significant correlation between emotional intelligence and mental health and aggression.(15)

Teaching emotional awareness is effective in regulating anger emotion and there is a relationship between emotional intelligence and anger and emotion. Kobman and Russell emphasize the moderating role of emotional intelligence in controlling aggression in the workplace.(16) Dong and Howard argue that emotional intelligence consists of a set of abilities that effectively empowers staff to efficiently respond to workplace stresses and emotional behaviours (Including anger) of themselves and others.(17)

\section{CONCLUSIONS}

According to the results of this study, creating a supportive environment by providing continuous training programs, adequate resources, limiting appointment time, as well as monitoring and accountability in patient care, are prerequisites for successful public health promotion and anger prevention. Having high emotional intelligence makes people able to adapt to challenges of their lives and effectively control their anger, thereby providing opportunities for improvement and enhancement of their mental health.

\section{REFERENCES}

[1] Kemp AH, Cooper NJ, Hermens G, et al. Toward an integrated profile of emotional intelligence: Introducing a brief measure. Journal of Integrative Neuroscience 2005;4(1):41-61.

[2] Bar-On R. Emotional intelligence and self-actualization. In: Ciarrochi J, Forgas JP, Mayer JD, eds. Emotional intelligence in everyday life: a scientific inquiry. Psychology Press 2001: p. 82-97.

[3] Hyland S, Watts J, Fry M. Rates of workplace aggression in the emergency department and nurses' perceptions of this challenging behaviour: a multimethod study. Australasian Emergency Nursing Journal 2016;19(3):143-8.

[4] Quinn CA, Rollock D, Vrana SR. A test of Spielberger's state-trait theory of anger with adolescents: Five hypotheses. Emotion 2014;14(1):74-84.

[5] Duncan SM, Hyndamn K, Estabrooks CA, et al. Nurses' experience of violence in Alberta and British Columbia hospitals. Canadian Journal of Nursing Research Archive 2001;32(4):57-78. 
[6] Esmaeilpour M, Salsali M, Ahmadi F. Workplace violence against Iranian nurses working in emergency departments. International Nursing Review 2011;58(1):130-7.

[7] Nelis D, Quoidbach J, Mikolajczak M, et al. Increasing emotional intelligence: How is it possible? Personality \& Individual Differences 2009;47(1):36-41.

[8] Knezevic B, Milosevic M, Golubic R, et al. Work-related stress and work ability among Croatian University hospital midwives. Midwifery 2011;27(2):146-53.

[9] Stichler JF. Emotional intelligence. A critical leadership quality for the nurse executive. AWHONN Lifelines 2006;10(5):422-5.

[10] Habibpur Z, Khorami MA. Emotional intelligence and application in nursing. Journal of Urmia Nursing and Midwifery Faculty 2005;3(4):156-66.

[11] Mohammadi SD, Qaraei B. Assessment of relationship behavioural disorders and emotional intelligence in students. Journal of Kerman University of Medical Sciences 2008;14(4):289-99. (In Persian)
[12] Sadock BJ, Sadock VA. Kaplan and Sadock's synopsis of psychiatry: behavioural sciences/clinical psychiatry. $10^{\text {th }}$ edn. Lippincott Williams \& Wilkins 2011.

[13] Mayor JCD, Salovery P. Selecting a measure of emotional intelligence. In: Baron IR, Parker J, eds. The Handbook of emotional intelligence. California: Jossey-Bass Inc. 2000: p. 321-42.

[14] Krane V, Williams JM. Psychological characteristics of peak performance. In: Williams JM, edr. Applied sport psychology: personal growth to peak performance New York: McGraw-Hill 2006;5:207-27.

[15] Rasouli Z, Eslami R, Khademi A. Evaluation of relationship between emotional intelligence and mental health and anger among the Air force personnel. Ebnesina 2015;17(1):56-9.

[16] Quebbeman AJ, Rozell EJ. Emotional intelligence and dispositional affectivity as moderators of workplace aggression. The impact on behaviour choice. Human Resource Management Review 2002;12(1):125-43.

[17] Dong Q, Howard T. Emotional intelligence, trust and job satisfaction. Competition Forum 2006;4(2):381-8. 